\title{
FRANCIA Y EL CONFLICTO DEL LIBANO
}

\author{
Clara M. Thomas de Antonio
}

Comprender la actual situación del Líbano no es tarea fácil. Es mucho lo que se ha escrito sobre una guerra que dura ya, de forma casi ininterrumpida, desde mediados de los años setenta y a la que no se ve salida, al menos de inmediato. Las causas de este conflicto hay que buscarlas tanto en acontecimientos recientes como remotos, y forman un entramado tan complejo y enmarañado que resulta difícil un análisis racional que pueda conducir a su solución. Este trabajo no pretende, ni mucho menos, dar una explicación definitiva que ni los más expertos analistas han conseguido; su objetivo es clarificar algunas de las razones históricas que subyacen en el conflicto y que pocas veces se mencionan.

Entre los factores más importantes de dicho conflicto, y sin entrar a valorar su peso relativo en el mantenimiento de la situación actual, se podrían citar los siguientes:

- El cambio de las estructuras demográficas: los cristianos están perdiendo su status de comunidad mayoritaria en favor de los musulmanes, y entre ellos de los chiíes, que están sobrepasando a los sunníes.

- Las desigualdades crecientes entre las diferentes capas de la población: ciertos elementos de las comunidades cristiana, sunní y drusa gozan de un status socio-económico más elevado que otras, especialmente la chií.

- La vecindad del Estado de Israel, fuertemente apoyado por los EEUU, y el enorme crecimiento de la población palestina del Líbano tras su expulsión de Jordania en 1970: La actividad armada de estos refugiados expone al Líbano a las represalias israelíes y pone en entredicho su soberanía. Los palestinos son, además, un apoyo para los partidos de izquierda que minan el poder de los líderes feudales tradicionales. Por ser musulmanes en su mayoría, también ponen en peligro el equilibrio establecido entre las distintas comunidades. En consecuencia, se ha producido la militarización de muchas organizaciones comunitarias.

- La situación geo-política del país en el Oriente Medio: la intervención de otros países, árabes y occidentales, en el conflicto ha convertido al Líbano en el escenario de una guerra por el predominio en la región. 
Además de estas causas, más o menos recientes, a las que cada día se añaden nuevos incidentes que enmarañan más la madeja, existen otras aún más profundas y remotas que están en la raíz de su desarrollo y en las que fue decisiva la actuación de Francia: la creación del Líbano como país independiente dentro de unas fronteras artificiales y la institucionalización del confesionalismo como sistema de participación en el poder.

La actuación de Francia fue similar a la de otras potencias occidentales en otros países de la región y por ello su análisis también puede ayudar a entender la inestabilidad política de un mundo árabe que sigue buscando soluciones a sus múltiples problemas estructurales.

Para comprender la creación del Líbano y el sistema confesional, hay que estudiar las relaciones de Francia con los cristianos libaneses y su papel durante la época del Mandato, todo ello en el marco de la intrincada historia de este pequeño país ${ }^{1}$, cuya supervivencia en tan dramática y prolongada situación no deja de ser sorprendente.

\section{El Libano precristiano.}

La situación geográfica del Líbano, en una encrucijada de caminos entre Oriente y Occidente y entre Norte y Sur, ha hecho de esta tierra lugar de encuentro de muchas civilizaciones. Por su peculiar morfología montañosa ha sido tierra de refugio y asilo de distintas comunidades en lucha contra la autoridad central o la ortodoxia religiosa.

Los fenicios, famosos como comerciantes, navegantes e inventores del alfabeto, dieron celebridad al Líbano muchos siglos antes de Cristo. Tras su disgregación, el Líbano no constituiría una entidad política separada hasta el s. XVI d. C. Como región de Siria ${ }^{2}$, junto a Palestina y Jordania, fue sometida al dominio de los asirios, persas, macedonios, romanos, árabes, francos, mongoles y turanios. Todos estos acontecimientos fueron acompañados de devastaciones y persecuciones alternadas con épocas de florecimiento y esplendor.

\section{Roma y el nacimiento del cristianismo.}

Ciertos principados habían conservado su autonomía bajo asirios, persas y macedonios, unidos a Antioquía por lazos de vasallaje. En el año 64 d. C. Pompeyo se adueñó de la región, formando la Provincia Romana de Siria, y Beirut se convirtió en un centro de cultura latina.

1 Para no alargar innecesariamente las notas se incluye al final del trabajo la bibliografia utilizada sobre la historia del Líbano, ordenada alfabéticamente. Sólo se citarán a pie de página aquellas notas que consideramos imprescindibles. Las citas serán abreviadas, ya que se trata de obras comprendidas en la bibliografía final. Por otro lado, se ha optado por una transcripción vulgarizada de los nombres propios o de ciertos vocablos árabes que facilite su reconocimiento al lector no especializado.

2 Hasta la creación del moderno estado del Líbano, es frecuente que los términos «Siria» y «sirios» se refieran también al Líbano y a sus habitantes. 


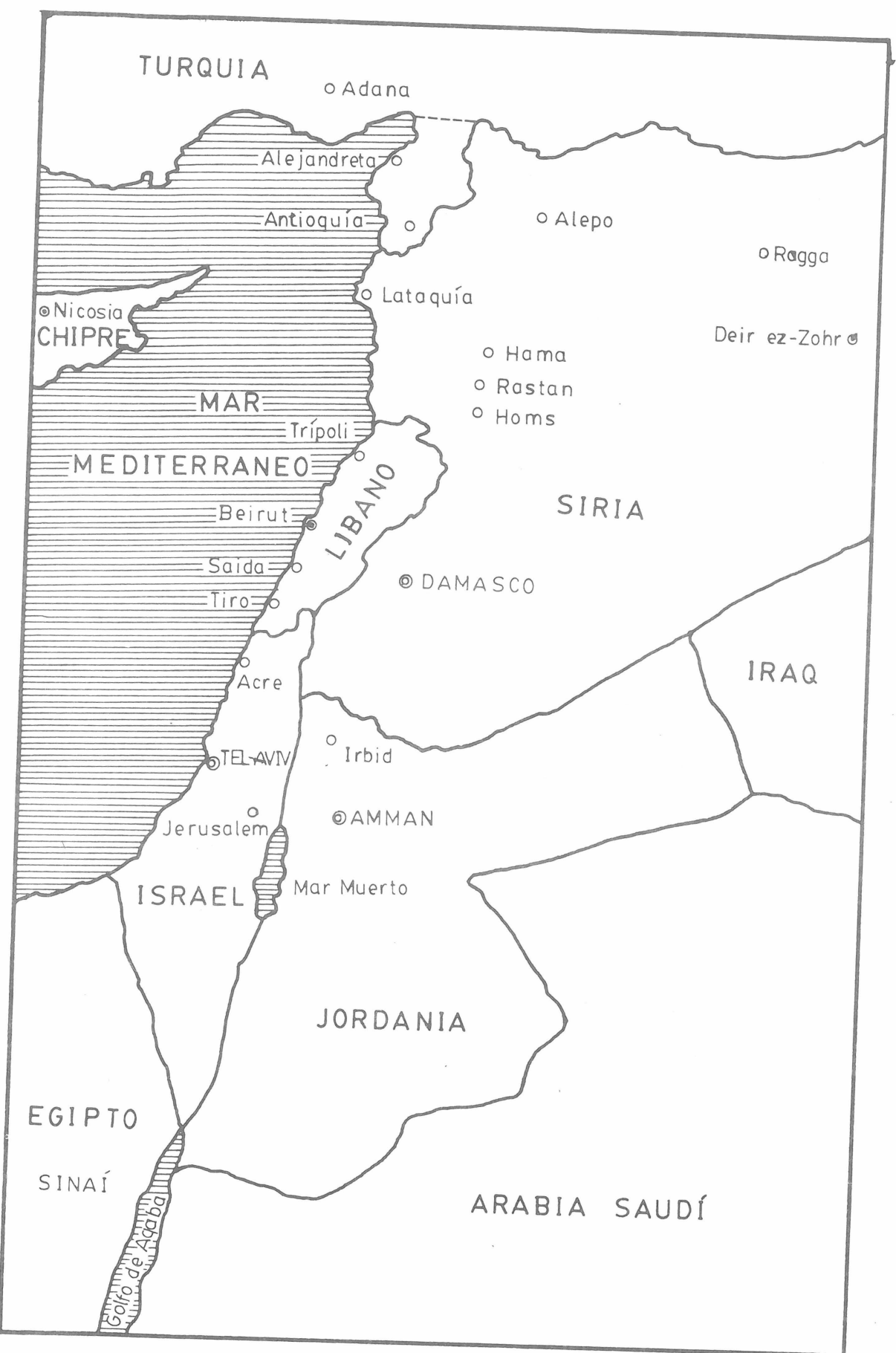




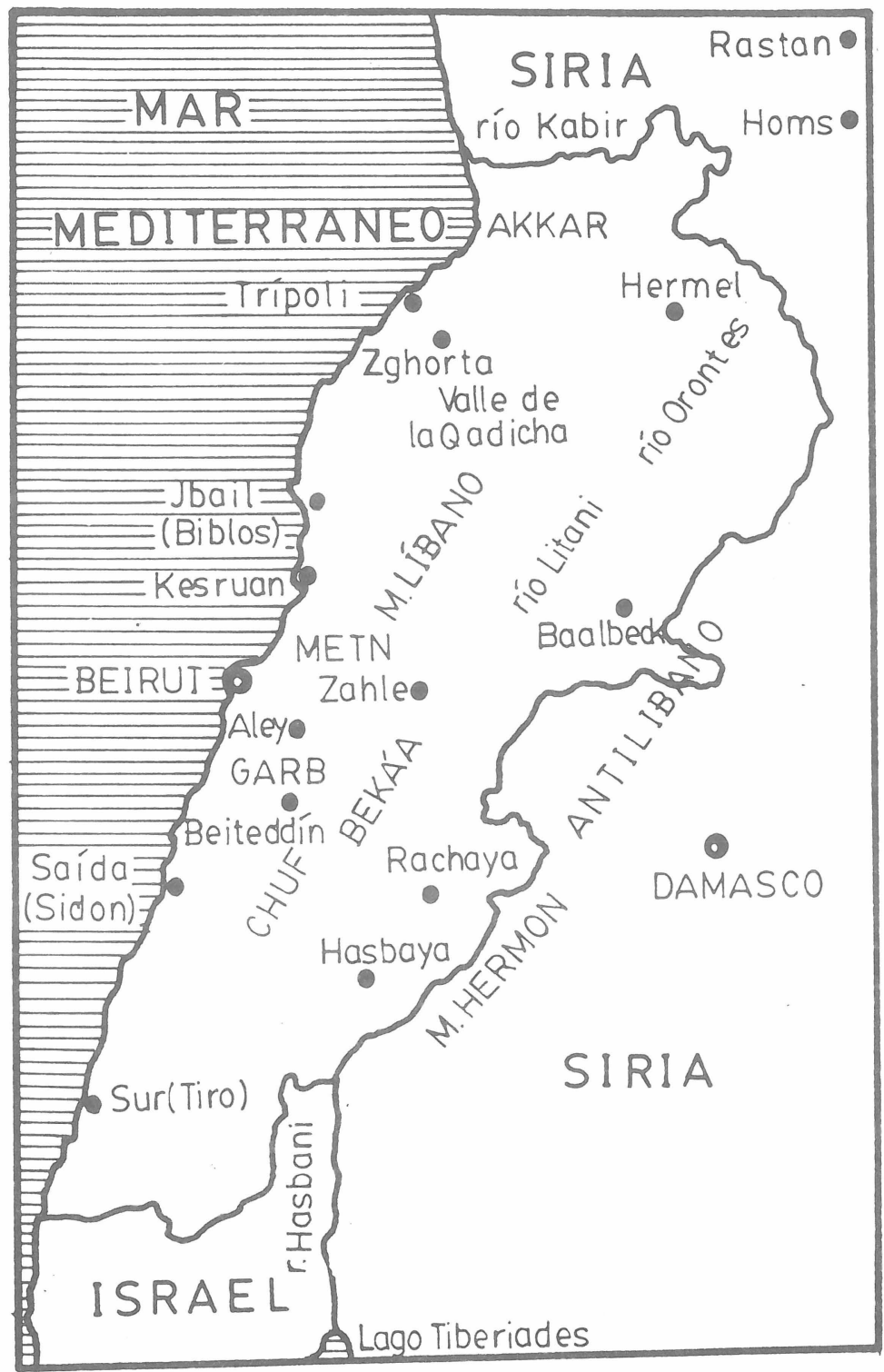


En esta época tuvo lugar un hecho histórico de gran importancia para la zona: el nacimiento del cristianismo. En un principio éste no se extendió con rapidez, porque los sirios estaban muy ligados a la mitología macedonia y romana. Su primer foco de expansión fue Antioquía. A partir del reinado del primer emperador cristiano de Roma, Filipo el Árabe, las conversiones se multiplicaron, afectando principalmente a arameos autóctonos y a ciertas tribus beduínas de Arabia, instaladas en Siria, como es el caso de los Tanuj.

\section{Bizancio y el desarrollo de las herejías.}

Cuando el Imperio Romano se dividió (395 d. C.) Siria pasó a formar parte del Imperio Bizantino. Fue dividida en tres provincias, quedando los territorios del Líbano actual repartidos entre dos de ellas. Beirut volvió a vivir una edad de oro hasta que un terremoto asoló la costa libanesa en el año 555.

Pero la zona de la montaña no pudo prosperar por la política de Bizancio, que impidió un desarrollo económico que habría podido ser brillante gracias a la introducción del gusano de seda,traído de la China en el s. IV, y a la extensión del arte de su cría. Esto hizo impopulares a los bizantinos entre la población autóctona y ayudó a preservar la lengua aramea, mientras el griego y el latín quedaban para usos no cotidianos.

De esta época datan también las primeras expatriaciones de comerciantes sirolibaneses, los cuales fundaron importantes colonias en Italia, España y sur de Francia. Otra consecuencia de la política autoritaria de Bizancio fue el desarrollo de herejías que empezaron a dividir al mundo cristiano: nestorianos, monofisitas, monotelitas, etc...

Árabes: Omeyas, Abbasíes y Fatimíes.

En esta situación, los árabes iniciaron su expansión por la región siro-libanesa sin encontrar resistencia. Los bizantinos huyeron y los conquistadores beduinos se asentaron en el interior, y no en la costa, por su tradicional miedo al mar.

Cuando Muawiya fundó la dinastía Omeya (661-750) y estableció su capital en Damasco, tomó el litoral para defenderse de un posible regreso de los bizantinos. Con el apoyo de los sirios, conquistó Acre, Trípoli y Tiro, instalando allí algunas guarniciones y a grupos de refugiados del Iraq que huían de su contrincante Alí. Este es el principal origen de la población árabe de los puertos libaneses.

Los cristianos no fueron perseguidos sino incorporados a la corte califal y a su administración. Su libertad de conciencia, sus iglesias y sus santuarios fueron respetados. Durante esta etapa la región siria fue el centro del mayor imperio del Islam.

Pero el Imperio Omeya pereció por las disensiones entre yemeníes y qaisíes, dos clanes beduinos que habían participado en la conquista. Los omeyas se apoyaban en los yemeníes y esto suscitó los celos de los qaisíes que, aliados con los 
chiíes iraquies partidarios de Alí, les vencieron y trasladaron la capital del imperio a Bagdad en el año 750.

Bajo el Imperio Abbasí (750-1258), la región siria perdió su esplendor, quedando relegada al nivel de simple provincia. Las primeras víctimas de la tiranía de los califas fueron los cristianos, que tomaron las armas y se sublevaron en Monaitira en el año 759. Fracasada la rebelión, los cristianos de raza árabe fueron forzados a convertirse al Islam. En adelante, y hasta el s. XVIII, los cristianos de Siria serían casi exclusivamente de raza aramea.

En el s. X el Imperio Abbasí se desdobló y surgió la dinastía fatimí (909-1171) en Egipto. Los bizantinos volvieron a conquistar Siria, aprovechando el desorden reinante. Cuando más tarde la abandonaran, Allaqa se había proclamado emir, y ejerció su dominio hasta que los fatimíes le vencieron. En esta época se produce la fundación del drusismo, secta musulmana que jugará un importante papel en la historia del Líbano.

A finales del s. XI, Alepo, Damasco y Jerusalem cayeron en manos de los turcos selyucidas, quedando la costa en poder de los fatimíes. En el país reinaba el caos, mientras los emires locales tiranizaban a la población. En ese momento, las comunidades del territorio libanés eran ya muy numerosas y estaban muy diferenciadas de la comunidad sunní, representante de la ortodoxia islámica. Entre las más importantes estaban la mardaíta, la maronita, la greco-ortodoxa, la chií y la drusa. Las sectas más hostiles al Islam ortodoxo se refugiaron en las montañas. Todo estaba listo para la aparición de las cruzadas.

Las cruzadas y los cristianos libaneses.

En el año 1098 los cruzados francos se apoderaban de Antioquia y durante dos siglos dominarían el Oriente Medio. Los emires del Líbano central tuvieron que practicar un difícil equilibrio, pactando tanto con los francos como con los pachás musulmanes, logrando así conservar sus dominios. Los francos, que resistieron largo tiempo los ataques musulmanes, terminaron sucumbiendo ante los mamelucos de Baybars a finales del siglo XIII.

El balance del gigantesco esfuerzo de los cruzados en Levante fue muy pobre desde el punto de vista religioso: perdieron la oportunidad de extender su religión entre los mongoles y, a través de ellos, por Asia; no hubo conversiones de musulmantes y las iglesias separadas no volvieron a la ortodoxia. Quizás dejaron en Levante menos cristianos de los que había cuando llegaron pues, tras su marcha, algunos maronitas que les habían apoyado desde el principio fueron perseguidos, otros huyeron con los francos y se instalaron en Chipre, y los que quedaron fueron deportados al interior. Sólo el odio de los mamelucos hacia los chiíes libró a los maronitas de una completa destrucción.

Sin embargo, la prolongada convivencia entre los francos y las poblaciones levantinas les llevó a conocerse, dando lugar no sólo a la agresión sino, a veces, a un respeto mutuo, a la amistad o a la colaboración. 
Mamelucos: comercio con los francos y consulados.

Aún más importantes para la futura relación de Francia con el Líbano serían los lazos comerciales que se crearon. El gusto de los francos hacia la vida oriental — sus perfumes y sus especias, su seda y su algodón, su azúcar, su pimienta o su incienso- creó un próspero comercio y dio lugar a la instauración de los Consulados, institución con múltiples consecuencias políticas que resistiría todas las pruebas durante siglos.

Los corsarios francos de Chipre y Rodas multiplicaban sus incursiones contra las costas sirias y esto obligó a los mamelucos a modificar la población costera para defenderlas: de Trípoli a Beirut las dejaron en manos de los turcomanos, y de Beirut a Saída, en manos de los emires del Garb.

Los mamelucos permitieron a los francos comerciar con Beirut y tener en esta ciudad iglesias, baños y hospedajes. Esto estimuló aún más el comercio; tras los navíos de Chipre vinieron otros de Venecia, Pisa, Florencia, Provenza y Cataluña. Los derechos de entrada y salida de estos navíos proporcionaban unas sustanciales rentas a los gobernantes de Damasco y Saída, de los que dependían los puertos de la costa, y parte de estas rentas iban destinadas a los mamelucos del Cairo.

Esto explica la institución de los consulados francos y de otros privilegios que fueron obteniendo, como la creación del derecho consular o de los tribunales consulares para los extranjeros. Este liberalismo se fue extendiendo hasta el aspecto religioso, y se permitió a los franciscanos abrir en Beirut un establecimiento para albergar a los peregrinos que se dirigían a Tierra Santa.

Así, Beirut, gracias a su magnífico puerto natural, gozó de más prosperidad que otras ciudades costeras, arruinadas por los cercos de los cruzados. Esta influencia de los francos jugaría un decisivo papel en la historia moderna y contemporánea del Líbano.

\section{Turcos Otomanos y emires Maán.}

En 1453, los turcos otomanos tomaron Constantinopla y acabaron con el Imperio Bizantino. Siria, sujeta al dominio mameluco, cayó en poder otomano a principios del siglo XVI y no se libraría de él hasta el año 1918 en que se derrumbó su imperio a consecuencia de la primera guerra mundial. Durante este período, los principados libaneses serían administrados por emires de las familias Maán (1516-1697) y Chehab (1697-1842) sucesivamente.

En la contienda entre turcos y mamelucos, los emires Tanuj del Garb no supieron ser tan habilidosos como sus antepasados y tomaron decidido partido por los mamelucos. Los emires Maán —drusos de origen kurdo o árabe instalados en el Chuf desde el s. XII, que hasta entonces habían pasado desapercibidostomaron partido por los otomanos. Su jefe, el emir Fajreddín I (1515-1545), recogió la herencia de los Tanuj y se convirtió en el gran señor del Líbano central. Pero ni él ni su hijo supieron conservar el favor otomano. 
Mientras tanto, el resto del país estaba dividido en pequeñas dinastías locales, toleradas por los otomanos, más preocupados en recaudar tributos que en los aspectos políticos de su gobierno. Estas dinastías locales estaban enfrentadas entre sí - situación azuzada a su vez por los otomanos- y el país vivió en medio de batallas, pillajes y asesinatos hasta que surgió una personalidad que supondría un hito en la historia del Líbano: el emir Fajreddín II (1585-1634), que durante medio siglo dominaría la región.

\section{Fajreddín II, fundador del Libano.}

Fajreddín era nieto del primer emir Maán. A la muerte de su padre tenía doce años y su madre le envió a educar a Kesruan para sustraerle al rigor otomano. A los dieciocho años tomó posesión de su feudo del Chuf. Odiaba a los turcos, que habían acabado con su padre y su abuelo, y se dedicó a combatirles con la fuerza y con la astucia.

Como su feudo era pequeño para enfrentarse a ellos directamente, empezó sometiendo a los feudos vecinos y extendiendo sus dominios más allá de los límites del Líbano contemporáneo. A la vez, desarrolló el comercio exterior y estableció alianzas militares secretas con Europa, dirigidas contra los turcos.

Actuaba como emir independiente y hostil, pero los turcos, ocupados en guerrear contra Persia y Hungría, toleraban su expansión, ya que pagaba sus tributos religiosamente, no atacaba las regiones administradas por ellos y sabía ganarse a los ministros de Estambul con regalos.

Sin embargo, cuando sobrepasó los límites tolerables, los turcos le atacaron y le obligaron a exiliarse durante cinco años, que aprovechó recorriendo Italia, visitando hospitales, arsenales y museos, y aprendiendo nuevos métodos bancarios y agrícolas. Cuando los turcos le permitieron volver, elevó su poder a límites legendarios, administró su país con sabiduría y siguió ampliando sus dominios. Pero, después de diecisiete años de gobierno, un nuevo ataque a los turcos acabó conduciéndole a un trágico final.

Al tiempo que un gran general, con un ejército eficaz, Fajreddín fue un excepcional constructor, administrador, diplomático y político. Embelleció Beirut y Saída con grandes palacios y jardines. En el Chuf y la Bekáa efectuó trabajos de irrigación. Fue el primero en crear imprentas en Levante para imprimir en árabe, siriaco, persa y copto. Como liberal, suprimió toda discriminación religiosa: mantuvo como ministro a un maronita, levantó las prohibiciones que pesaban contra los cristianos y les permitió construir conventos.

Pero su auténtico mérito fue la fundación del Líbano, haber hecho un Estado de unos principados dispersos. Bajo su administración reunió los territorios que hoy forman el Líbano y extendió su autoridad más allá de sus límites. Fue nombrado por el sultán otomano «Soltan al-barr», es decir, Sultán del Continente, con autoridad sobre todos los árabes desde Alepo a Jerusalem. Por primera vez se ligó en vasallaje directo a la Sublime Puerta, con tal independencia que hasta llegó a establecer relaciones diplomáticas con Florencia, Francia, España y Malta. 
Según la valoración de muchos historiadores, no sólo creó el Líbano político sino también el Líbano moral: bajo su administración las diversas comunidades constituyeron un mismo pueblo y vivieron solidariamente. Aunque sucumbió y sus fronteras se borraron, el Líbano sería, desde entonces, una realidad.

\section{Los emires Chehab.}

Tras la ejecución de Fajreddín en Estambul, los turcos entregaron la administración a un sobrino suyo, Melhem (1635-1657), que fue sucedido más tarde por su hijo Ahmed (1657-1697). Durante casi medio siglo ambos administraron el país con el talante liberal de su predecesor, aunque estrechamente vigilados por los turcos.

$\mathrm{Al}$ morir Ahmed sin descendencia masculina, los sultanes otomanos estaban demasiado ocupados con Europa para poner al Líbano bajo administración directa. Los emires de la región se reunieron y eligieron a un sobrino de Ahmed, Bechir I (1697-1706), emir de la rama de Rachaya de la familia Chehab, familia descendiente del Profeta, asentada en la zona siro-libanesa desde los tiempos de la expansión árabe. Bechir administró el país con sabiduría y dejó un recuerdo de señor valiente y generoso y de buen administrador. Pero murió envenenado por el nieto de Ahmed, Haydar, un Chehab de la rama de Hasbaya. Él y sus descendientes mantuvieron durante cerca de un siglo la tradición guerrera de los emires Maán, con un ejército tan temido como el de Fajreddín, llegando a dominar incluso a poderosos pachás otomanos.

La familia Chehab se dividió en dos ramas, ambas representadas en la actualidad: la rama cristiana maronita y la rama musulmana sunní. El primer emir cristiano de la familia, Yusuf, tuvo un gobierno difícil. Sometido a las exigencias de Yazzar — que significa «el Carnicero»—, un duro pachá de Saída que estaba al servicio de los otomanos, tuvo que imponer fuertes impuestos a los libaneses, que pronto se rebelaron. Fue sustituido por su intrigante sobrino Bechir II (1788-1840, también maronita, al que había acogido en su corte.

\section{Bechir II, El Grande.}

La primera mitad del s. XIX estuvo dominada por la figura de Bechir. Aunque le llamarían «el grande» tras cincuenta años de administrar el país, al principio fue rechazado por los libaneses por sus viles maniobras. Gracias al apoyo de Yazzar, el Carnicero, y del partido de Bechir Yumblat, y tras triunfos sangrientos, se hizo con el dominio del país. Pero el apoyo del pachá era caro y también se vio obligado a imponer fuertes impuestos. Por otro lado Yazzar incitaba contra él al hijo de Yusuf, para mantener divididos a los emires libaneses.

Sin embargo, la llegada de Napoleón a Palestina fue providencial para él. Aquél esperaba el apoyo de los cristianos libaneses, pero Bechir obró sagazmente de modo que la Sublime Puerta le confirmó en su puesto tras la retirada de Napo- 
león, aunque Yazzar siguió dudando de su fidelidad y hostigándole hasta que murió cinco años más tarde (1804). Entonces empezó realmente el reinado de Bechir, que fue aliado fiel de los turcos hasta la llegada del egipcio Mohamed Alí a Siria.

Bechir tuvo un enorme poder, llegando a convertirse, a pesar de grandes dificultades internas, en el árbitro del territorio. Viéndose obligado a veces a dejar el gobierno y retirarse, volvía con más fuerza, llegando a tener más prestigio que cualquier otro emir o pachá de la región.

Cuando Mohamed Alí comenzó su política de conquistas, invadiendo parte del Imperio Otomano, Bechir le ayudó, pero su ayuda no recibió un buen pago. La dura política que impusieron los egipcios llevó a los pueblos sometidos a amotinarse. Tras la victoria de M. Alí sobre el ejército turco en Nizib, las potencias occidentales temieron su expansión y decidieron actuar, fomentando una revuelta general en el Líbano.

Hasta los maronitas, relativamente favorecidos por los egipcios, tomaron partido contra ellos. Las diversas comunidades insurgentes - maronitas, grecoortodoxos, drusos y musulmanes - firmaron una histórica alianza en el santuario de Antelías, el día 8 de Junio de 1840. Francia tuvo que permanecer al margen del conflicto para no enfrentarse con los maronitas. Las otras potencias impusieron a M. Alí las condiciones de la Sublime Puerta: su dominio se limitaría a sus estados de Egipto con carácter hereditario y, pasajeramente, a Acre.

Bechir vio perdida su ya menguada autoridad y abdicó en 1840 . Se exilió a Malta y después a Estambul, donde murió en 1851, rico y rodeado del respeto de sus antiguos enemigos. Los libaneses le llamarían «el Grande» a pesar de su comienzo y final. Fue cruel con sus enemigos y tolerante con su pueblo. Sus ejércitos estuvieron presentes en todas las batallas de Levante. Supo mantener la paz religiosa y favorecer la solidaridad de las comunidades. Extendió la red viaria y los acueductos, construyó un fastuoso palacio en Beiteddín, hizo de Beirut una ciudad próspera y supo administrar bien el país. Junto a Fajreddín II, se le considera fundador del Líbano y el último de los grandes príncipes de la montaña.

$\mathrm{Al}$ abdicar, los ingleses proclamaron gobernador del Líbano a otro emir Chehab y jefe insurgente, Bechir III (1840-1842). Las revueltas y la intervención extranjera crearon un clima de anarquía y las divisiones internas, atizadas por la política inglesa — deseosa de impedir la vuelta de Francia a Levante-, dejaron sin efecto los pactos de Antelías. Con el apoyo de los turcos, los drusos resurgieron con fuerza, y sus choques con los cristianos abrasaron la montaña libanesa. Bechir, debilitado en su poder y aterrado por la acción turca de desarmar a los cristianos y dejarlos masacrar por los drusos, abdicó.

\section{Administración directa turca.}

Con Bechir III acabó el dominio de los emires Maán y Chehab sobre la montaña libanesa, pues los turcos pusieron la zona en régimen de administración directa, a cargo del renegado austriaco Omar Pachá. Pero este nombramiento de un extrajero suscitó vivas protestas en las montañas y la intervención de las potencias extranjeras. 
La Sublime Puerta retiró a Omar, pero no cedió a la propuesta de Francia y de los libaneses de nombrar a un emir Chehab. En 1843 decidió dividir el país en dos subprefecturas o qaimacamat: La zona al norte de la línea Beirut-Damasco, de mayoría maronita, sería administrada por un maronita, dependiendo del $p a$ chalik de Beirut, y la zona sur, de mayoría drusa, sería gobernada por un druso, dependiendo del pachalik de Saída.

Pero en ambos territorios existían importantes minorías: la drusa del Metn en el norte y la maronita del Chuf en el sur. Tras unos años de paz, la sinuosa política turca condujo a una serie de terribles matanzas de cristianos a manos de los drusos $(1841,1843,1860)$, que fueron posibles por la descomposición social de los cristianos, a consecuencia de la revuelta campesina contra los señores feudales. Los drusos, con sus estructuras sociales intactas y bajo el mando de sus jefes al-Atrach y Yumblat, atacaron diversos poblados cristianos y masacraron a sus habitantes. El exterminio se extendió a Siria, y en pocos días, más de veinte mil cristianos habían perecido.

El genocidio de 1860 conmovió a Europa. Las escuadras francesas e inglesas se dirigieron hacia Beirut y los turcos, que habían permitido las matanzas, se vieron obligados a tomar medidas para restablecer la paz, medidas más encaminadas a contentar a Europa que a hacer justicia. Los franceses reavituallaron a los cristianos libaneses, les ayudaron a reconstruir sus casas y dieron un nuevo impulso a las obras benéficas, a los hospitales y a las escuelas.

\section{Autonomía de la montaña libanesa.}

En 1864, las potencias elaboraron un Estatuto para el Líbano, que quedaría, no con un gobernador indígena, como pretendía Francia, sino con las condiciones impuestas entre ingleses y turcos: la montaña constituiría un sanyaq autónomo, directamente dependiente de la Sublime Puerta, gobernado por un católico no libanés nombrado por los turcos y asistido por un Consejo representativo de las comunidades. El orden estaría en manos de una gendarmería indígena con instructores franceses.

Al territorio se le amputaron la zona de Wadi Taym, cuna de los Chehab, el valle de la Bekáa, cultivado por los campesinos libaneses, y los puertos de Beirut y Saída, salidas marítimas de la montaña, como manera de impedir cualquier veleidad autonómica. Pero este Estatuto consagraba la unidad administrativa de la montaña, que vivió en paz hasta 1914, con una población de 415.000 habitantes, de los cuales 330.000 eran cristianos y de ellos 240.000 maronitas.

\section{Fin del dominio turco.}

En la primera guerra mundial, Turquía declaró la guerra a los aliados y acabó con el régimen de autonomía libanés impuesto por Francia. Durante los cuatro años de la guerra, el Líbano sufrió una dura política turca: la simpatía hacia 
los aliados y el autonomismo libanés eran castigados con la muerte. El bloqueo aliado, el hambre y las epidemias diezmaron a la población. Tras la victoria aliada de Sarona, el 19 de septiembre de 1918, los turcos se retiraron de la costa libanesa y los aliados entraron en Siria y Líbano. En Beirut, los habitantes les aclamaron y en pocos días el Líbano se vio liberado del yugo turco.

De nuevo los franceses tuvieron que reavituallar al pueblo exhausto y detener la epidemia de tifus que los diezmaba. También acabaron con las pretensiones de soberanía de los seguidores de Feisal, hijo del Jerife de la Meca, a quien los aliados habían prometido proclamar rey de los árabes como pago por su ayuda en la lucha contra los turcos. La ruptura de esta promesa nunca sería olvidada en Levante, sembraría la semilla de la desconfianza hacia Europa y crearía el primer gran trauma contemporáneo de la nación árabe.

\section{Mandato francés.}

Tras diversos tratados y conferencias de paz, Siria y Líbano quedarían confiados a la tutela de Francia. El tratado de Versalles, del 8 de Junio de 1919, en que se firmó el Pacto de la Sociedad de Naciones instaurando el régimen de Mandatos, decía en su artículo 22:

«Los principios siguientes se aplican a las colonias y territorios que, tras la guerra, han dejado de estar bajo la soberanía de los Estados que los gobernaban anteriormente y que están habitados por pueblos aún incapaces de dirigirse a sí mismos en las condiciones particularmente difíciles del mundo moderno. El bienestar y el desarrollo de estos pueblos forman una misión sagrada de civilización, y conviene incorporar en la presente acta las garantías para el cumplimiento de esta misión.

El mejor método de realizar en la práctica este principio es confiar la tutela de estos pueblos a las naciones desarrolladas que, en razón de sus recursos, de su experiencia o de su posición geográfica, sean las mejores para asegurar esta responsabilidad y que consientan en aceptarla: ejercerán esta tutela en calidad de Mandatarios y en el nombre de la Sociedad [de Naciones] (...)

Ciertas comunidades que antes pertenecían al Imperio Otomano [Siria, $\mathrm{Pa}$ lestina, Mesopotamia] han alcanzado tal grado de desarrollo que su existencia como naciones independientes puede ser reconocida provisionalmente, a condición de que los consejos y la ayuda de un Mandatario guíen su administración hasta el momento en que sean capaces de conducirse solas. Los deseos de estas comunidades deben ser tomados en consideración para la elección del Mandatario.... ${ }^{3}$.

Esta resolución, nacida de la imposibilidad de perpetuar el estilo de dominio colonial, reconocía implícitamente la independencia de estas naciones. Sin embargo, este espíritu relativamente liberal de ayuda y consejo no sería respetado en los siguientes textos relativos al Mandato. Por ejemplo, en la Declaración de 29 de septiembre de 1923, en la que se especificaban los términos de dicho Man-

3 Rabbath, 1928, p. 49. 
dato sobre Siria y Líbano, y que sentaría las bases del desarrollo constitucional del territorio, Francia se reservaba, en un texto de una calculada ambigüedad, un poder ilimitado de decisión y de supervisión que la convertía en autoridad absoluta, deformaba esa «misión sagrada de civilización» y acababa con el espíritu humanitario y liberal que parecía haber inspirado el pacto de 1919.

La política antiárabe, antimayoritaria y antinacionalista de Francia la llevaría a fragmentar la "Gran Siria» en pequeños estados, a entregar Alejandreta a los turcos (1939), a fomentar las rivalidades confesionales favoreciendo a ciertas minorías, y finalmente a separar la zona litoral (el Líbano), de mayoría cristiana, de la zona del interior (Siria), de mayoría musulmana.

\section{Creación del estado del Libano.}

A Francia se le plantearon varios problemas al asumir el Mandato. Podía organizar la antigua provincia otomana de Siria, de la que ya se había desgajado Palestina, en un solo Estado o dividirlo en dos: Siria y Líbano. En el caso de optar por la segunda alternativa, ¿cuáles serían las fronteras? ¿cuál sería la estructura política del país?

El Líbano era considerado como la fachada marítima de Siria, pero Francia decidió convertirlo en Estado independiente, como se lo había prometido al patriarca maronita Hayek en 1919, dejando el resto del país dividido en tres Estados federados: Damasco, Alepo y el país de los Alauíes. Así, el 1 de septiembre de 1920, el General Gouraud proclamaba la independencia del Líbano.

Para establecer sus fronteras, Francia podía elegir entre el Monte Líbano, que había gozado de una cierta autonomía con los otomanos, o el Líbano del emir Fajreddín. Aunque la elección era difícil, optó por esta segunda alternativa, la creación del Gran Líbano, cuyos límites, fijados en 1926, ya no se han modificado y son los que enmarcan a la actual República Libanesa. De esa manera al Pequeño Líbano o Montaña libanesa se le dio su desembocadura marítima, además de las tierras de trigo de la Bekáa, como nos lo confirma este expresivo texto del historiador Palazzoli:

«Uno de los fundamentos de la influencia de Francia en Levante había sido, desde hacía siglos, su relación privilegiada con las poblaciones cristianas. Así pues, era natural que se viera tentada, una vez echados los turcos de la región, a hacer prevalecer el deseo de estas poblaciones de administrarse en un cuadro autónomo, con la esperanza de que, por su mediación, la difusión de los intereses franceses sería garantizada en una zona tan esencial en tantos aspectos.

Pero un Pequeño Líbano, limitado a los bastiones maronitas de la montaña, no era viable (...). La anexión al Monte Líbano del llano de la Bekáa y de las ricas llanuras costeras de Trípoli, Tiro y Saída, regiones musulmanas, permitirían remontar la dificultad, dotando al país de una larga fachada marítima y de zonas rurales prósperas, haciéndolo de tal suerte c^e, en el nuevo conjunto, los cristianos fueran mayoritarios» ${ }^{4}$. 
No menos expresivo es este otro texto del diplomático Charles-Roux, que expone, con mayor rotundidad aún, las auténticas razones de la separación del Líbano del resto de Siria.

«Cuando Francia separa política y administrativamente al Líbano de la Siria propiamente dicha, agrandándolo, (...), dándole Beirut por capital, procediendo a la organización de ese nuevo estado del Gran Líbano, distinto e independiente, donde los cristianos (...) están aún en mayoría, ¿qué hace sino asegurar el futuro a los cristianos libaneses que había protegido ab antiquo, tener en cuenta las diferencias étnicas, religiosas e intelectuales que les distinguen de los árabes del interior, preservándoles de la fusión con una masa extranjera a su nación (...), realizando las aspiraciones maronitas que habían quedado insatisfechas? (...).

Cuando Francia rehusa admitir una monarquía siria en provecho de un miembro de la familia del jerife de la Meca y abre las hostilidades contra el emir Feisal (...), ¿qué hace aún sino atar corta una ambición panarábiga que amenazaba a la vez a la autoridad mandataria y a la seguridad de los cristianos de Siria? ${ }^{5}$.

En cuanto a la organización política, Francia optó por un Estado comunitario en el que las comunidades estarían representadas en los empleos públicos y en la composición de los ministerios, del gabinete y del parlamento, de forma proporcional a su importancia numérica. Esta institucionalización del «confesionalismo», que en aquel momento era el único medio que tenía Francia para proteger a la población cristiana, mayoritaria en el Monte Líbano, será una de las bases principales del conflicto actual, ya que la proporción numérica ha variado de manera importante, pero no su representación en el poder.

Tan crucial será este problema que desde 1932 no se ha elaborado un censo de población (Ver cuadro 1), ya que demostraría que el equilibrio confesional en que se basa toda la organización política no responde a la realidad del país. No existen cifras oficiales y las que proporcionan las distintas fuentes difieren entre sí, variando según se tenga en cuenta o no a los refugiados palestinos, musulmanes en su mayoría, o a los libaneses de la emigración, en gran parte cristianos. En 1983, una de estas fuentes estimaba que la población musulmana constituía ya el $60 \%$ de la población libanesa, pues los musulmanes eran aproximadamente 1.950 .000 mientras los cristianos sólo eran $1.150 .000^{6}$.

\section{Comunidades.}

La población libanesa estaba, y sigue estando, compuesta por un rico mosaico de comunidades, distribuidas de forma irregular por todo el territorio (ver cuadro 2) y representadas según las proporciones que aparecen en el cuadro 3.

6 The Middle East and North Africa, 1984, p. 507. 


\section{Cuadro 1: CENSO DE LA POBLACIÓN LIBANESA EN 1932}

\begin{tabular}{|c|c|c|c|}
\hline Maronitas................. & 227.800 & & $28,53 \%$ \\
\hline Greco-ortodoxos ......... & 77.312 & & $9,68 \%$ \\
\hline Greco-católicos.......... & 46.709 & .................. & $5,85 \%$ \\
\hline Armenio-ortodoxos..... & 25.462 & .................. & $3,18 \%$ \\
\hline Armenio-católicos ...... & 5.694 & …............. & $0,72 \%$ \\
\hline Protestantes ............... & 6.712 & ................... & $0,85 \%$ \\
\hline Siro-católicos.............. & 2.675 & & $0,34 \%$ \\
\hline Siro-ortodoxos........... & 2.574 & & $0,32 \%$ \\
\hline Caldeos-católicos......... & 528 & & $0,06 \%$ \\
\hline Total cristianos..... & 395.466 & & $49,54 \%$ \\
\hline Sunníes .................... & 178.130 & & $22,31 \%$ \\
\hline Chiíes ...................... & 155.035 & & $19,42 \%$ \\
\hline Drusos..................... & 53.334 & …............ & $6,68 \%$ \\
\hline Total musulmanes.. & 386.499 & & $48,41 \%$ \\
\hline Judíos...................... & 9.981 & & $1,27 \%$ \\
\hline Otros........................ & 6.301 & ................... & $0,80 \%$ \\
\hline
\end{tabular}

Fuente: J. P. Pontalis: Pluralism and Party Transformation in Lebanon. Leiden, 1974. Citado por López García, 1985, pp. 128-129.

Cuadro 2: DISTRIBUCIÓN GEOGRÁFICA POR SECTAS EN 1956

\begin{tabular}{|lrrrrr|}
\hline & Beirut & Montaña & \multicolumn{1}{c}{ Norte } & \multicolumn{1}{c}{ Sur } & Bekáa \\
\cline { 2 - 6 } & 76.116 & 24.423 & 118.203 & 29.889 & 37.067 \\
Sunníes.......... & 18.101 & 224.921 & 111.917 & 39.509 & 29.260 \\
Chironíes............. & 17.062 & 22.716 & 1.337 & 148.466 & 61.044 \\
Drusos........... & 2.457 & 71.569 & 19 & 6.893 & 7.193 \\
Greco-ort........ & 25.276 & 32.239 & 62.767 & 10.784 & 17.861 \\
Greco-cat....... & 3.617 & 21.520 & 3.864 & 23.147 & 35.630 \\
\hline
\end{tabular}

Fuente: D. C. Gordon, 1980, p. 42. 


\section{Cuadro 3: DISTRIBUCIÓN DE LOS ESCAÑOS PARLAMENTARIOS POR SECTAS (de 1943 a 1972)}

\begin{tabular}{|rrrrrrr|}
\hline & 1943 & 1947 & 1951 & 1953 & 1957 & $1960-72$ \\
\cline { 2 - 7 } Maronitas ....... & 18 & 18 & 23 & 13 & 20 & 30 \\
Greco-ort....... & 6 & 6 & 8 & 5 & 7 & 11 \\
Greco-cat....... & 3 & 3 & 5 & 3 & 4 & 6 \\
Armenio-cat.... & 2 & 2 & 3 & 2 & 3 & 4 \\
Minorías........ & 1 & 1 & 3 & 1 & 2 & 3 \\
\cline { 2 - 7 } T. cristianos.... & 30 & 30 & 42 & 24 & 36 & 54 \\
Sunníes........... & 11 & 11 & 16 & 9 & 14 & 20 \\
Chí́es........... & 10 & 10 & 14 & 8 & 12 & 19 \\
Drusos........... & 4 & 4 & 5 & 3 & 4 & 6 \\
\cline { 2 - 7 } T. musulmanes. & 25 & 25 & 35 & 20 & 30 & 45 \\
\cline { 2 - 7 } T. general. & 55 & 55 & 77 & 44 & 66 & 99 \\
\hline
\end{tabular}

Fuente: C. K. Chehab: Les élections législatives de 1968. Beirut, 1968, pp. 30-32. Citado por López García, 1985, p. 140.

El origen y la trayectoria histórica de la comunidad maronita son bastante discutidos por los especialistas. La creación de la Iglesia maronita data del año 685 y su nombre procede del monje Marún. Si es cierto que habían defendido la herejía monotelita, volvieron a la obediencia romana en el año 1182. Los maronitas habían sufrido los ataques de los emperadores bizantinos y tuvieron que abandonar Antioquía, remontar el Orontes y establecerse en Rastán, entre Homs y Hama. La invasión árabe les hizo emigrar de nuevo y atrincherarse en las montañas del Líbano Norte, en el Valle Santo o Valle de la Qadicha, en el s. VII. Desde allí se extendieron hacia Kesruan y Jbail y a los feudos drusos de Metn y Chuf. A partir de este núcleo, y tras mezclarse con los autóctonos greco-fenicios de la costa, los arameos del interior, los mardaítas, los francos y los armenios de los momentos de las cruzadas, constituyeron la actual comunidad maronita. En torno a ella se creó el Estado del Líbano, en el que ocupan una situación preeminente por su número, cultura y actividad. En la montaña son agricultores y en la ciudad comerciantes, funcionarios o de profesiones liberales. Forman la mayor parte de la burguesía de Beirut.

Los greco-ortodoxos son los descendientes de los habitantes del Líbano en época bizantina. Son los libaneses más antiguos, pues son arameos más puros que los maronitas, que se habían mezclado con diversas comunidades a lo largo del tiempo. Sin embargo, por su comportamiento, son los cristianos más árabes del país, especialmente en los terrenos cultural, ideológico y político. 
Los greco-católicos son una comunidad formada a partir de una escisión de los greco-ortodoxos, a principios del s. XVIII, y se les encuentra en algunos pueblos del Chuf, de Zahlé y otros que rodean la Bekáa y Beirut.

Los armenios ortodoxos o gregorianos, de raza indoeuropea, son originarios de la Anatolia oriental y emigraron al Líbano en época reciente. En 1914 apenas eran unos tres mil. Huyendo de los turcos, llegaron al Líbano en oleadas sucesivas: en 1918, al evacuar los franceses la Cilicia, y en 1939, al ceder Alejandreta a los turcos. Tras vivir en condiciones miserables, lograron ocupar un lugar destacado entre los comerciantes de Beirut. Hoy forman una buena parte de la clase media libanesa, juegan un escaso papel político, a excepción de una minoría, y han conservado fuertemente su organización comunitaria.

Los armenios católicos, desgajados de los gregorianos en el s. XVIII, juegan un papel político más importante. Otras minorías cristianas son la siro-católica, la siro-ortodoxa, la romana católica y la protestante, de escasa importancia en la vida del país.

Entre las comunidades musulmanas, los representantes de la ortodoxia islámica son los sunníes, cuya historia va ligada a la expansión del Islam. Están repartidos a lo largo de la costa, con grupos muy numerosos en Beirut y Trípoli, y tienen una gran importancia en la vida del Líbano. Es una comunidad relativamente más próspera, educada y urbana que los chí́es, pero en la actualidad son inferiores numéricamente a estos últimos.

Entre los grupos chí́es, disidentes del Islam, surgidos entre los años 656 y 661, destacan los metualíes que, procedentes del interior de Siria, se extendieron por la Bekáa, los montes de Akkar, el norte de Palestina y la región de Tiro. Luego se establecieron en Kesruan y en el llano de Beirut. Actualmente ocupan las mismas zonas.

Los ismailíes, otro grupo disidente y fiel al Aga Kan, apenas están representados en el Líbano actual, pero dieron origen a otra disidencia importante: los drusos. La rama de los nosairíes, ansaríes o alauíes, situada en el extremo de la ortodoxia del Islam, desapareció posteriormente del Líbano y se replegó a la montaña alauí y a Lataquía, que forman parte de la actual Siria.

Los drusos, cuyo origen es también muy discutido, surgieron con las predicaciones de Hamza y Darrazi, dos enviados del califa fatimí que fundó la secta. Estos enviados se detuvieron en Hasbaya y Rachaya, zonas repletas de grupos chiíes. Los nosairíes les fueron hostiles, pero tuvieron éxito entre los ismailíes. Tras eliminar a Darrazi — personaje de donde procede la denominación de drusoHamza llevó su predicación hasta Alepo y, para evitar las disensiones internas y la hostilidad musulmana exterior, decidió cerrar la secta definitivamente. En el s. X los drusos de Alepo y de Wadi Taym (Hasbaya y Rachaya), se agruparon en el norte del Líbano, en el Chuf, en Metn y en el Garb, que aún siguen siendo sus hábitats. Sus dotes guerreras les hicieron dueños de las montañas y les permitieron conservar sus particularismos. Más tarde, parte de los drusos se establecieron en el Haurán, al sur de la Siria actual, que hoy día alberga a la mitad de la comunidad. 


\section{La República Libanesa.}

En 1926, el Estado del Gran Líbano se convertía en la República Libanesa, en virtud de la proclamación de la primera Constitución del Líbano que, modificada parcialmente en 1927 con la supresión del Senado, sigue siendo la base de la Constitución actual.

En aquel momento también se estableció la tradición — ratificada después en el llamado Pacto Nacional y no recogida en ningún texto legal, pero respetada con raras excepciones hasta hoy día- de un ejecutivo compuesto por un Presidente de la República maronita, un Presidente del Consejo sunní, un Presidente de la Cámara de Diputados chií y un Vice-presidente de la Cámara greco-ortodoxo.

Durante todo el Mandato, la relación de Francia con el Líbano fue más tranquila que su relación con Siria y el país gozó de un período de prosperidad sólo oscurecido por algunas nubes: una crisis política en 1932, que llevó al Alto Comisario francés a suspender la Constitución, y el rechazo del Parlamento de Francia al tratado de 1936 que debía poner fin al Mandato, pues aprobar el del Líbano suponía aprobar también el tratado franco-sirio. Durante este período se continuó la labor de equipamiento e infraestructura, iniciada por los franceses en el s. XIX, con la ampliación de la red viaria y de los ferrocarriles, con la mejora del puerto de Beirut y con el desarrollo de los servicios educativos y asistenciales.

Pero este período de calma se vió interrumpido en 1941 por los acontecimientos de la segunda guerra mundial. El Líbano fue escenario de los violentos combates de los ingleses y los franceses partidarios de la Francia libre contra las tropas de Vichy de la Francia ocupada, causando enormes pérdidas y devastaciones.

\section{La Independencia.}

Tras la victoria de los aliados sobre las tropas de Vichy, el general Catroux proclamó solemnemente la independencia del Líbano el día 25 de diciembre de 1941. Pero las circunstancias de la guerra impidieron que esa declaración se convirtiera en realidad. Este retraso, la lucha entre los propios franceses y las intrigas inglesas para eliminar la influencia francesa en la región, desprestigiaron a la potencia mandataria ante el pueblo libanés.

En esas condiciones, las elecciones de 1943 llevaron al Líbano y a Siria cámaras nacionalistas que, desde las primeras sesiones, decidieron suprimir de la Constitución los poderes de Francia. El Delegado General francés reaccionó deteniendo al Presidente del Gobierno libanés, Bichara al-Juri, al Presidente de la Cámara, Riad Solh, y a varios ministros.

Este gesto, poco razonable teniendo en cuenta que el poder real estaba en manos de los ingleses, tuvo como consecuencia la formación de un «Gobierno de resistencia» en la montaña Libanesa y la firma del Pacto Nacional, en que las distintas comunidades confirmaban la antigua «entente» de la Jornada de Antelías. Este Pacto constituiría la Carta comunitaria del Líbano en la que se basaría toda su política posterior. En él, los cristianos se comprometían a no pedir ayuda 
y asistencia a Occidente y los musulmanes a no luchar por llevar al Líbano a la órbita árabe.

Ante esta situación, el General Catroux, enviado rápidamente por De Gaulle a Beirut, hizo liberar a los detenidos. Esta medida restableció la calma, pero el poder de Francia sobre el Líbano y Siria ya estaba sentenciado. En 1945 los últimos servicios pasaban a depender del gobierno libanés y en 1946 la evacuación de las tropas francesas e inglesas llegaba a su fin.

A pesar de la tormenta de 1943, no se alteraron profundamente las relaciones de Francia y el Líbano. El día que París fue liberado la Montaña libanesa lo festejó. Aunque Francia ya no volvería a gozar del poder y la influencia internacional que había tenido, y que había pasado a manos de otras potencias, seguiría siendo considerada como la protectora de los cristianos de Levante.

\section{Los primeros años de Independencia.}

La tarea que debían enfrentar las nuevas autoridades indígenas no era fácil. El Presidente Bichara al-Juri (1943-1952), maronita, y el Presidente del Consejo, Riad Solh, sunní, consolidaron la estructura confesional del Líbano, aún de mayoría cristiana. La calma reinó hasta el asesinato de Solh a manos del Partido Popular Sirio, un partido de carácter fascista que pretendía la integración del Líbano en la Gran Siria.

El equilibrio conseguido en los primeros años de independencia se debilitó al faltar el contrapeso musulmán, encarnando por la fuerte personalidad de Riad Solh. El poder del Presidente maronita se encontró sin ese freno; el favoritismo hacia su clientela y la exclusión de los musulmanes en la distribución de las prebendas, suscitaron la oposición de éstos y de otros clanes cristianos, rivales de al-Juri, también desplazados de las posiciones lucrativas. Estos abusos del clan presidencial le abocaron a una creciente impopularidad.

En el Parlamento, la oposición se organizó en una coalición heterogénea que agrupaba a socialistas y capitalistas, a nacionalistas árabes y a amigos de las potencias occidentales. Las maniobras de la coalición y una huelga general en el país acabaron con el régimen corrupto de al-Juri, que se vió obligado a dimitir y a dejar el gobierno en manos del general Fuad Chehab, que se encargó de convocar unas nuevas elecciones.

Esta crisis puso de relieve la debilidad del edificio comunitario, fundado en un frágil equilibrio de clanes y comunidades. En la elección del nuevo Presidente maronita, Camille Chamún (1952-1958), surgió una nueva semilla de odio en el clan de su opositor y rival, Hamid Frangie, también cristiano, que cuatro años más tarde, se aliaría con Naser en contra de Chamún.

La creciente ascensión del arabismo hizo surgir las primeras tensiones islamocristianas. La comunidad musulmana había aumentado de forma sustancial y el sistema confesional podía haberla favorecido. Por ello reaccionó con hostilidad ante las críticas que empezaron a surgir frente al confesionalismo. 
Nuevas complicaciones, como las aspiraciones sirias a la anexión, las intrigas político-militares, los pactos que dividieron al mundo árabe, la triple agresión del Israel, Francia e Inglaterra en la crisis de Suez, la doctrina Eisenhower, etc..., pusieron en peligro el difícil equilibrio libanés, sus relaciones con el mundo árabe y occidente y su propia independencia.

El alineamiento de Chamún a la doctrina Eisenhower y su deseo de renovar su mandato, prohibido por la Constitución por sus efectos desequilibrantes sobre la política del país, provocaron una oposición que acabó en una violenta insurrección en 1958 que le obligó a dimitir.

De nuevo tuvo que ser el general Fuad Chehab (1958-1962), el único capaz de reunir los fragmentos del Líbano en torno a su persona, el que tomara las riendas: formó un gobierno que integraba a todas las fuerzas revolucionarias e intentaba restablecer el equilibrio perdido. Sin embargo, los cristianos reaccionaron violentamente, provocando una contra-revolución, pues el nuevo gobierno no daba ninguna garantía a la independencia e integridad del Líbano.

En esta crisis de 1958, de revolución y contra-revolución, se pusieron de relieve no sólo las rivalidades entre clanes y comunidades sino también un problema más profundo: el enfrentamiento de dos nacionalismos, encarnados por las dos grandes comunidades; la maronita, defensora a ultranza del independentismo libanés y prooccidental, y la sunní, partidaria de un mayor acercamiento e integración con los países árabes. Sólo un gobierno que estuviera formado por el jefe sunní de la revolución, Rachid Karamé, y el jefe maronita de la contrarevolución, Pierre Gemayel, podría restablecer la calma y permitir unos años de relativa prosperidad, hasta que un nuevo acontecimiento provocara una nueva crisis.

Algunas consideraciones finales.

La historia de los primeros años de independencia sirve de botón de muestra de las siguientes etapas, que sería demasiado largo exponer aquí y que quedaban fuera de nuestro objetivo inicial. El precario equilibrio del Líbano se vería roto en numerosas ocasiones, hasta culminar con el estallido de la llamada «guerra del Líbano», en 1975. A partir de entonces, el país va a vivir en permanente situación de guerra, de todos conocida, que ha provocado ríos de tinta y de sangre.

La vida libanesa se irá haciendo cada vez más compleja: a la lucha por el poder de las distintas comunidades se añadirán las rivalidades entre distintos clanes de una misma comunidad; frente a la autoridad casi exclusiva de los señores feudales libaneses, surgirán los líderes de partidos políticos de nueva implantación, que darán al conflicto religioso un fuerte carácter socio-económico; la situación fronteriza con el Estado de Israel y la presencia cada vez más numerosa de refugiados y combatientes palestinos en su suelo, extenderán el conflicto a la región; la lucha de ciertos países árabes y de las potencias occidentales por la supremacía, le darán su carácter internacional. 
Otros conflictos internos muy complejos y cambios sucesivos en el panorama internacional oscurecen aún más la comprensión del conflicto actual, pero no deben hacernos olvidar algunas de sus raíces más profundas: la creación del Líbano moderno y el sistema confesional, en las que Francia jugo un papel crucial. Francia delimitó sus fronteras artificiales con la intención de proteger los intereses de los cristianos libaneses y los suyos propios. La separación política del Líbano del resto de la Gran Siria, que ha dividido a familias antes pertenecientes a un sólo país, nunca ha sido aceptada por los partidarios del nacionalismo pansirio, que la consideran como una amputación de la Siria histórica a la que se ha desprovisto de gran parte de su fachada marítima y de su territorio más fértil: de ahí el papel de Damasco a lo largo del conflicto.

Por otro lado, al fijar las fronteras de forma que la población mayoritaria fuera cristiana, el sistema confesional como base de acceso al poder favorecía a esta comunidad, pero el cambio demográfico producido en los años siguientes a favor de los musulmanes ha puesto en peligro la supremacía cristiana. Su posición privilegiada en los terrenos político, cultural, económico y social, ha suscitado la hostilidad creciente de las comunidades menos favorecidas y la defensa encarnizada de esa posición por parte cristiana. La necesidad de pertenecer a una determinada comunidad para acceder a ciertos cargos impide que los desempeñen los más aptos, estanca la evolución política del país e imposibilita encontrar una vía de solución al conflicto.

\section{BIBLIOGRAFÍA}

Alem, Jean Pierre: Le Liban. P.U.F. París, 1968.

BAR, Luc Henri de: Les communautés confessionnelles du Liban. Ed. Recherches sur les civilisations. París, 1983.

Charles-Roux, F.: France et Chrétiens d'Orient. Flammarión, París, 1939.

DAHDAH, Nagib: Evolución histórica del Libano. Oasis. México, 1964.

Desjardins, Thierry: Le martyre du Liban. Librairie Plon. París 1976.

Fichas del Mundo Árabe. Nicosia. (Varios años).

GHANEM, Hanna: Une solution pour le Liban. Système vital integré et valorisation personelle. Ed. Didon. Quebec, 1980.

Gordon, David C.: Lebanon. The fragmented nation. Londres, 1980.

Haddad, Jean Pierre: Liban, le courage d'exister. Maisonneuve. París, 1978.

Khoury, Enver M.: The crisis in the Lebanese System. Confessionalism and Chaos. American Enterprise Institute for Public Policy Research. Washington, D. C., 1976.

Longrigg, S. H.: Syria and Lebanon under French Mandate. Oxford University Press. Londres, 1958. 
LÓPEZ GARCÍA, Bernabé y FERNÁNDEZ SUZOR, C.: Introducción a los regímenes y constituciones árabes. Centro de Estudios Constitucionales. Madrid, 1985.

OwEn, Roger, ed.: Essays on the crisis in Lebanon. (Varios autores). Ithaca Press. Londres, 1976.

Palazzoli, Claude: Syrie, le rêve et la rupture. Le Sycomore, París, 1977.

PINO, Domingo del: Crónica de una guerra civil. Diecinueve religiones y un solo cementerio. Argos-Vergara, Barcelona, 1983.

RABBATH, Edmond: L'evolution politique de la Syrie sous Mandat. Marcel Rivière, ed. París, 1928.

The Middle East and North Africa. 1984-1985. Europa Publications Ltd. Londres, 1984.

TiBAwi, A. L.: A Modern History of Greater Syria, including Lebanon and Palestina. Macmillan. Londres, 1969.

TuENI, Ghassan: Une guerre pour les autres. J. C. Lattès. París, 1985.

Von Grunebaum, Gustave E.: El Islam II: Desde la Caída de Constantinopla hasta nuestros días. 3. ed. Historia general del s. XX. Ed. s. XXI. Madrid-Méjico, 1981 (1971). 